\title{
Henry James's Grandly Vague and Abstract Periodic Style and Its Partial Reversal in The Ambassadors*
}

\author{
Ling Wang \\ School of Foreign Languages \\ Yunnan University \\ Kunming, P. R. China
}

\begin{abstract}
Henry James partially reverses his grandly vague and abstract periodic style with fewer periodic sentences, abstract subjects, and non-transitive verbs late in The Ambassadors to imply that the protagonist Strether has changed his vague vision. He adopts elegant variation to delay the specification of the referents. The strategy of periodic postponement operates in the larger matters of characterisation, theme and plot arrangement, as well as in the sentence structure. James's periodic structure is embodied in the arrangement of the climactic revelation in the river scene nearly at the end of the novel. The enlightenment regarding his periodic sentences and the whole plot comes retrospectively at the end where all the complicated elements of meaning and scene fit synoptically into a whole. An apparent complication of James's style may find its justification in its integral and comprehensive thematic implications, and the resulting surprising and ironical effects. Henry James is great as a modern periodic master.
\end{abstract}

Keywords-Henry James; The Ambassadors; Strether; grandly vague and abstract periodic style; climactic revelation

\section{INTRODUCTION}

According to Alistair Campbell's criterion, writers whose works contain periodic sentences may be considered as having a periodic style even though complete periodic sentences are few in their works [1]. Analogously, the term "periodic" may still be retained for a periodic sentence whether rigorously complete or nearly so. "Periodic" is now generally accepted as a term referring to anticipatory constituents, and is adopted to refer to any style in which

*This paper was supported by China's 2017 national funds for social sciences research under the arts project "An iconography of ethnic music and dance images found in southwest China", number 17EH248; China Scholarship Council under the 2015 research project "The intercultural comparison, translation and communication of traditional ethnic cultures", number 201507035007; Yunnan province's 2015 planning funds for philosophy, social sciences and art under the key research project "The resource preservation, industry development and international exchange of the culture and art of ethnic music and dance images in Yunnan", number A2015ZDZ001; Yunnan University's 2016 research funds for teaching innovation under the project "An exploration into the development of internationalized courses: the course 'intercultural communication' as a forerunner", number 2016Y01; Yunnan University's 2013 funds for the construction of excellent postgraduate textbooks under the project of writing the textbook entitled Intercultural Communication in English: Theory and Experience; and Yunnan University's 1st series of the program for excellent young talents. anticipations habitually occur.

In The Ambassadors (1903), one of the three late novels by Henry James (1843-1916), such anticipations recur successively in the syntax, and have their counterparts in the plot and characterization. James uses long parenthetical constituents here and there in his periodic sentences to delay the subjects, predicate verbs or their objects, and names of the referents. Some sentences include more than one such parenthesis. The long delay in completion and specification in his periodic sentences makes the sense vague until the final appearance of the main grammatical components and the final identification of the referents. Furthermore, the periodic delay of revelation and the consequent vague sense are also realized on a larger scale in the plot-building and personality-portraying of the characters in The Ambassadors. Suspense is always present as to the characters' relationships and their characteristics. The vague sense resulting from the syntactic delays is cumulative and underlies the vagueness in the plot-building and characterization.

\section{A SAMPLE ANALYSIS OF JAMES'S GRANDLY VAGUE AND ABSTRACT PERIODIC STYLE AND ITS PARTIAL REVERSAL IN THE AMBASSADORS}

The novel The Ambassadors by Henry James is composed mainly of the delineations of the consciousness of the protagonist Strether and the dialogues between the characters. The first paragraph of Chapter IV, Book XI, in which the climactic river scene takes place, will be chosen for a sample analysis of James's grandly vague and abstract periodic style and its partial reversal to reflect the changing process of Strether's consciousness. To facilitate the reference in the analysis, the sentences in the paragraph will be numbered as follows.

(1) What he saw was exactly the right thing - a boat advancing round the bend and containing a man who held the paddles and a lady, at the stern, with a pink parasol. (2) It was suddenly as if these figures, or something like them, had been wanted in the picture, had been wanted more or less all day, and had now drifted into sight, with the slow current, on purpose to fill up the measure. (3) They came slowly, floating down, evidently directed to the landing-place near their spectator and presenting themselves to him not less clearly as the two persons for whom his hostess was already preparing a meal. (4) For two very happy persons he found 
himself straightway taking them - a young man in shirtsleeves, a young woman easy and fair, who had pulled pleasantly up from some other place and, being acquainted with the neighbourhood, had known what this particular retreat could offer them. (5) The air quite thickened, at their approach, with further intimations; the intimation that they were expert, familiar, frequent - that this wouldn't at all events be the first time. (6) They knew how to do it, he vaguely felt - and it made them but the more idyllic, though at the very moment of the impression, as happened, their boat seemed to have begun to drift wide, the oarsman letting it go. (7) It had by this time none the less come much nearer-near enough for Strether to dream the lady in the stern had for some reason taken account of his being there to watch them. (8) She had remarked on it sharply, yet her companion hadn't turned round; it was in fact almost as if our friend had felt her bid him keep still. (9) She had taken in something as a result of which their course had wavered, and it continued to waver while they just stood off. (10) This little effect was sudden and rapid, so rapid that Strether's sense of it was separate only for an instant from a sharp start of his own. (11) He too had within the minute taken in something, taken in that he knew the lady whose parasol, shifting as if to hide her face, made so fine a pink point in the shining scene. (12) It was too prodigious, a chance in a million, but, if he knew the lady, the gentleman, who still presented his back and kept off, the gentleman, the coatless hero of the idyll, who had responded to her start, was, to match the marvel, none other than Chad. [2]

The shift of tone in the paragraph can be matched with the change in the formal structure of James's style. The former six sentences, which display Strether's consciousness in his customary mood of sensitive but indulgent and idealizing appreciation, conform to the general pattern of James's grandly vague and abstract periodic style in The Ambassadors. The sixth sentence typically begins with the protagonist's "vaguely" feeling something. However, Sentences 7 to 12 deviate from the general stylistic pattern in certain ways.

In his analysis of the opening paragraph of The Ambassadors, Ian Watt summarizes the following Jamesian features: a preference for non-transitive verbs; many abstract nouns; much use of "that"; a certain amount of elegant variation to avoid piling up personal pronouns and adjectives such as "he", "him", and "his"; and the presence of a great many negatives and near-negatives [3]. Opening paragraphs of novels are not necessarily linguistically representative, but Watt's summary accords with the characteristics of James's style in The Ambassadors. It is interesting that the distinctive features match the former six sentences more closely than the latter six of the first paragraph of Chapter IV, Book XI.

The epithet "the right thing" in the first sentence of the excerpt obviously reminds the reader of all the frequent vague allusions to "the thing" and "other things" in The Ambassadors. The cliché "the thing" is a treacherous medium of communication, concealing as much as it reveals. It certainly serves as a double-edged weapon in the hands of an innocent abroad like Strether. The Oxford English Dictionary lists the following meanings for "the thing": a. the correct thing; what is proper, benefiting, or fashionable; also of a person, in good condition, or "form", "up to the mark", fit (physically or otherwise); b. the special, important, or notable point; esp. what is specially required. The cliché is loaded with Strether's sensitive impressions of the river scene. On the one hand, it indicates some lack of discrimination since his impressions are vague and uncertain. On the other hand, he applies a morally neutral and signally vague epithet as a term of the highest praise to suggest the precariousness of his elected stance as an ambassador.

The appearance of the boat seems to be "the right thing" to Strether because it accords with his sense of the total harmony of the scene. However, what appears to be "the right thing" in his idealized vision turns out to be altogether the wrong thing. The images of the couple in the boat come into sharper focus, and prove to be not two vague images "in the picture", but particular persons in particular circumstances that concern Strether very closely. Indicated by the sharp shock of his realization, the ironical double effect of Strether's impressions is to undermine the inflated authority of "the thing". When his impressions are attached to two anonymous figures, they are agreeable. However, when the two figures turn out to be Chad and Madame de Vionnet, the same impressions become evidence of moral turpitude. Strether is in fact betrayed into full knowledge of the unpleasant truth by his own characteristic habit of watching and thinking.

The cited paragraph does not contain many abstract words, but does include some of those found most characteristically in James's accounts of Strether's consciousness in The Ambassadors, such as "intimations", "intimation", and "impression", which occur in the former six sentences to display Strether's consciousness in his customary mood of sensitive but indulgent appreciation. The protagonist approvingly recognizes in the "young" couple an example of that "beauty" which has haunted him throughout his stay in Europe. The drifting wide of the boat at the end of Sentence 6, however, disturbs this impression. The word "though" makes the change clear and prepares for Strether's recognition of Chad and Madame de Vionnet. The pink parasol, formerly a purely pictorial element, is now a device of deception, "shifting as if to hide her face" (Sentence 11). The imposition of human feelings on an inanimate parasol delicately indicates Strether's complex feelings at this point. Having realized the couple's motive for concealment, he tries to attribute it to the inanimate parasol.

Watt counts fourteen non-transitive verbs as against only six transitive verbs in the opening paragraph of The Ambassadors [3]. Sentences 1 to 6 of the first paragraph of Chapter IV, Book XI have nearly the same ratio: thirteen non-transitive verbs vs. eight transitive verbs. The thirteen non-transitive verb forms are as follows: "was" (2) ${ }^{1}$, "had been wanted" (2), "had drifted", "came", "had pulled up", "thickened", "were", "wouldn't be", "knew", "happened", and "seemed". The eight transitive verb forms are "saw", "held", "was preparing", "found", "had known", "offer",

In the following analysis, the number in parentheses indicates the incidence of occurrence of a word or an expression. 
"felt", and "made". However, in Sentences 7 to 12 there is a more even balance: twelve non-transitive verbs vs. ten transitive verbs. The twelve non-transitive verb forms are as follows: "had come", "had remarked", "hadn't turned round", "was" (5), "had wavered", "continued", "stood off", and "kept off". The ten transitive verb forms are as follows: "had taken account of", "had felt", "had taken in" (3), "knew" (2), "made", "presented", and "had responded to". The counts exclude the infinitives, participles and gerunds. In Sentences 1 to 6 there are fourteen such subordinate verb forms, but in Sentences 7 to 12 there are only ten.

James's preference for non-transitive, participial, infinitive, and gerundial verbs is associated with an abatement of the active nature of the subject + verb + object syntax, and with an avoidance of concrete and particular subjects. This is generally true of the former six sentences in the excerpt. The subjects are vague and tentative, for example, "What he saw ..." (Sentence 1), "It ..." (Sentence 2); or the subject "he" is delayed by the unusual word order, for example, "For two very happy persons he found himself straightway taking them ..." (Sentence 4), "They knew how to do it he vaguely felt ..." (Sentence 6).

In contrast, in Sentences 8 to 11 there are a succession of regular subject + verb + object constructions, with concrete and particular subjects in three of the four cases: "She had remarked on ..." (Sentence 8), "She had taken in ..." (Sentence 9), "This little effect was sudden ..." (Sentence 10), "He too had within the minute taken in ..." (Sentence 11).

R. W. Short calculates the average length of the 196 sentences in Chapter II, Book II of The Ambassadors to be 35.3 words when counting up to the period [4]. Watt finds out the average length of the sentences in the opening paragraph of The Ambassadors to be 41 words [3]. In the first paragraph of Chapter IV, Book XI, Sentences 1 to 6 have a length of $32,42,34,46,28,41$ words respectively, giving an average of just over 37. Sentences 7 to 12 have a length of 35, 28, 24, 27, 35, 48 words respectively, giving an average of just under 33 . What pushes up the latter average is the long Sentence 12, in which Strether is struggling to regain his former equilibrium, and to work up some pleasure at the turn of events. His actual apprehension of the odd, disturbed behaviour of the couple in the boat is appropriately conveyed in the shorter Sentences 8, 9 and 10.

Two negative expressions appear in the former six sentences and three in the latter six. The former two are stylistically more significant than the latter three. "Not less clearly" (Sentence 3) and "wouldn't at all events be the first time" (Sentence 5) are characteristic of Strether's hesitant, elaborately qualified trains of thought. "None the less" (Sentence 7), "hadn't turned round" (Sentence 8), and "none other than" (Sentence 12) do not have such emphasis.

The latter part of the paragraph displays Strether's changing consciousness, violated by the facts that he has hitherto failed to recognize in his absorption in beauty. The change is conveyed by James's partial violation of his own stylistic norms of The Ambassadors at the moment of climactic revelation. Watt comments that James tends to "express states of being rather than particular actions affecting objects" [3]. The stylistic norms of The Ambassadors are related to the writer's concern with the mental rather than the physical state of the protagonist. James's stylistic norms and their functions are applied to the former six sentences of the discussed paragraph, which is knitted into the fabric of the novel by a number of periodic stylistic threads. Then in the latter six sentences James violates his periodic stylistic norms in order to portray particular objects affected by concrete actions. More real events emerge in the latter six sentences with a stark, unadorned clarity that is rare in The Ambassadors. There is much less vagueness and abstractness after the climactic and dramatic revelation scene on the river.

\section{JAMES'S PERIODIC DEVICE OF ELEGANT VARIATION TO DELAY THE SPECIFICATION OF THE REFERENTS}

Henry James adopts his periodic device of elegant variation a great deal to delay the specification of the couple in the boat in the above cited paragraph. The elegant variations of the images are listed as follows: "a man ... and a lady"-_"these figures"—-"they"-_the two persons"-_"two very happy persons"- "a young man in shirt-sleeves, a young woman easy and fair"_- "the oarsman"- "the lady", "her companion"_- "the lady, the gentleman"-_the coatless hero of the idyll"- "Chad".

The image of "young man in shirt-sleeves" in Sentence 4 becomes "the gentleman, the coatless hero of the idyll" in Sentence 12 , and the name of the referent is not identified until the very end of the paragraph. The image of a coatless gentleman in James's supremely dressed world is a gentleman caught off his guard, whereas being "in shirtsleeves" suggests only appropriate casualness and freedom. The negative formulation "coatless" implies incongruity, indiscretion and vulnerability. The image of "hero" in this context changes into a mock-heroic description. James is describing three characters, two of whose names he will not reveal until the very end of the paragraph. The variations referring to the three images in the river scene are either natural enough to be unobtrusive: "spectator" (Sentence 3), "oarsman" (Sentence 6), "companion" (Sentence 8), or, like the variation from "man" (Sentence 1) to "gentleman" (Sentence 12), charged with some dramatic and ironical implications.

The only example of obvious elegant variation, "our friend" (Sentence 8), has the effect of making the reader identify with Strether at the very moment when the couple in the boat seem to be forming an alliance against him. There is irony in the fact that the observations regarding Chad and the identification of his name occur in a sentence that begins with the suggestion of a pleasant surprise: "It was too prodigious, a chance in a million ...". In the last sentence of the paragraph, the reader gets a premonition of that tension between what all the parties know to be the embarrassing truth and the agreeable appearance which they try to put onto it. 


\section{THE IMPLICATIONS AND EFFECTS OF JAMES'S PERIODIC STYLE AND ITS PARTIAL REVERSAL}

The river scene functions as a climax in which Strether's vague vision is violated by the truth. After the scene there are fewer instances of the characteristic Jamesian periodic structure but more cases of his uncharacteristic adoption of the subject + verb + object structure. More facts are coming out directly through Strether's consciousness and his dialogues with other characters. Though his reaction to the discovery of Chad's sexual intimacy with Madame de Vionnet is not one of disgust, the kind of response which belongs to the moral world of American Woollett where he comes and which he has abandoned forever, Strether's situation is cleared up by the shock of recognition.

Strether meets Chad and Madame de Vionnet by the river, and realizes belatedly that their relationship is after all a common illicit liaison. Having committed himself completely to the idea of social elegance, Strether faces the painful truth that it is sustained by those people who are also human beings, with all their vulgar weaknesses. After the river scene, his appreciation of those social values in Europe is mingled with a wry mockery of his previous innocence in America. The reversal in Strether's heuristic progress does not diminish his image in the reader's eyes. He is ennobled as well as chastened by his disillusionment. The trouble with his vision is not so much that it is false as that it is too pure for anyone else but himself to live up to. The glamorous face value which Paris symbolizes for Strether is partially deceiving. Throughout the novel the majority of the descriptions before the climactic revelation scene are in fact deliberately vague. It is just the very word "vagueness" that Strether himself employs to characterize his long-standing vague, idealizing illusions about the Chad-Madame de Vionnet relationship after it has been exposed by their encounter on the river: "... he almost blushed, in the dark, for the way he had dressed the possibility [of a sexual liaison] in vagueness, as a little girl might have dressed her doll" [2]. The revelation scene forces Strether to revise his vision of social finesse. The ways in which James modifies his style to disperse the protagonist's vague vision highlight the effects and significance of his unique grandly vague and abstract period style.

Strether also has some dim apprehension of the other characters' superior powers and actions, which are represented by the rare intrusion of a few transitive verbs in the first paragraph of Chapter IV, Book XI. They are introduced to denote the odd and disturbed reaction of Chad and Madame de Vionnet in the boat. The change of Strether's vague vision and his enlightenment are partly reflected by the appearance of the rare transitive verbs in the revelation scene late in the novel.

However, the transitive effects of the transitive verbs which begin to appear after the river scene in the novel are often reduced by the Jamesian periodic adverbial insertions, and the relationship between direct cause and effect is thus weakened. The following are two examples: "He [Strether] was to reflect later on and in private that it was mainly he who had explained - as he had had moreover comparatively little difficulty in doing" [2]; "and indeed he [Strether] was to remember further still, in subsequent meditation, many things that, as it were, fitted together" [2].

The dominance of abstract and non-human things over animate and particular persons as the subjects of the periodic sentences is often a key to Strether's vague and abstract vision. The concrete and particular subjects emerging in the river scene toward the end of the novel help to imply that more realistic facts are coming out, and that Strether has changed his vague, idealizing vision to a more realistic one.

\section{CONCLUSION}

The periodic structure tends to postpone to its end the new, relatively important and climactic element. The strategy of periodic postponement operates in the larger matters of characterisation, theme and plot arrangement, as well as in the sentence structure, in The Ambassadors. James's periodic structure is embodied in the arrangement of the climactic revelation in the river scene in Chapter IV, Book XI, nearly at the end of the novel. By the agency of the merest coincidence, admittedly the stuff of fiction or farce, Strether's months of surmises are resolved in the instant of his shock at witnessing the illicit sexual liaison between Chad and Madame de Vionnet.

Apart from its dramatic effect, James's periodic structure has the related virtue of concentrating significance at a later point in both the sentences and the plot because the interpretation of anticipatory constituents is delayed in the periodic structure. The enlightenment regarding his periodic sentences and the whole plot comes retrospectively at the end, where all the complicated elements of meaning and scene fit synoptically into a complete whole. Thus an apparent complication of James's grandly vague and abstract periodic style, especially his predilection for parenthetical constructions, may find its justification in the integral and comprehensive thematic implications, and the resulting surprising and ironical effects that it creates. In a word, as seen from The Ambassadors, Henry James is great as a modern periodic master.

\section{ACKNOWLEDGMENT}

Special thanks go to the Center for Intercultural Studies, Saint Louis University, US where the author of the present article participated in the project "Multidisciplinary Approaches to the Study of Interculturality" as a visiting professor in 2016.

\section{REFERENCES}

[1] W. Minto, A Manual of English Prose Literature: Biographical and Critical, Designed Mainly to Show Characteristics of Style. London: William Blackwood \& Sons, 1872, p. 6.

[2] H. James, The Ambassadors. Middlesex: Penguin Books Ltd, 1986, pp. 461-462, p. 468, p. 327, p. 328.

[3] I. Watt, "The first paragraph of The Ambassadors: an explication," Essays in Criticism, Vol. X (3), 1960, pp. 250-274.

[4] R. W. Short, "The sentence structure of Henry James," American Literature, Vol. 18, No. 2, 1946, pp. 71-88. 